\title{
The Opinions of Science Teachers on the Weaknesses and Strengths of LGS and TEOG Systems (The Case of Kars Province)
}

\author{
Emine Hatun Diken ${ }^{1, *}$ \\ ${ }^{1}$ Department of Science Education, Kafkas University, Kars, Turkey \\ *Correspondence: Department of Science Education, Kafkas University, Kars, Turkey. E-mail: \\ hatundiken06@gmail.com
}

Received: April 2, 2020

Accepted: April 15, 2020 Online Published: April 30, 2020

doi:10.5430/jct.v9n2p20

URL: https://doi.org/10.5430/jct.v9n2p20

\begin{abstract}
This study aims to determine the opinions of science teachers working in secondary schools in Kars province of Turkey regarding the comparison of the High School Entrance Exam (LGS) which is currently being applied in Turkey and the transition from primary to secondary education (TEOG) which was applied in Turkey before this exam system. The study was conducted with a screening model and data was collected through structured questions. The study group consists of 48 Science Teachers, who have teaching experience "1-10, 10-20 and over 20 years", working in 13 different secondary schools in Kars. The main categories were tried to be determined using explanatory and inferential codes that appeared in the analysis of forms for teachers' views. As a result of the research, it was found that most science teachers expressed the opinion that it was not necessary to abolish the TEOG and enact the LGS, and that the TEOG exam served its purpose better than the LGS. Again, as a result of the research, it was found that science teachers who thought that TEOG was a stronger test than LGS expressed the opinion that TEOG should be more systematic, process-oriented, be compensated, have more impact on written exams in school, and that the exam should be a process-oriented exam spanning two semesters. It was determined that science teachers who thought that LGS was a stronger test than TEOG had expressed the opinion that LGS was a highly distinguishable test and that LGS questions were questions based on high-level thinking, high selectivity, based on interpretation, requiring knowledge, far from recitation, covering all subjects.
\end{abstract}

Keywords: high school transition exam, transition from primary to secondary education exam, science teachers

\section{Introduction}

To train time-integrated individuals to respond to the needs of society, some innovations were needed in the education system. The main one of these innovations is the examination systems which aim to select and place students according to certain criteria (Dinc, Dere and Koluman, 2014). Education is the foundation of social and individual development in an age of technology where knowledge is seen as strong. There are constant changes and development in education. One of the main objectives of the training field is to improve the components of the system and to repair the system (Ozkan, Guvendir, and Satici, 2016). To repair the system in Turkey, it is often inevitable that central exams should be carried out. In Turkey, all measurement-evaluation activities that include a certain part of any course at the local and central level or that cover more than one course in a local sense are called exams (Cepni, Ozsevgec, and Gokdere, 2003). In our country, large-scale exams are also applied in addition to classroom tests in measuring student achievement. While the results of large-scale exams are taken into consideration in directing education policies, in our country these exams are used to place students in a higher institution. Among these large-scale exams, one of the most well-known is the central exams conducted in the selection of students to secondary education institutions (high schools) (Ozkan and Guvendir, 2018). These exams remain important and are on the agenda as large-scale exams involving almost half of Turkey's population (Can, 2017). The common feature of these exams is that they consist of multiple-choice questions and are evaluated centrally at the same time (Can, 2010). Exams are conducted to determine whether the targeted gains in the education system are realized in students, and with the scores obtained as a result of these exams, students can be placed in a higher education institution (Yapic1, 2016). In addition to central exams, various measurements and evaluations are conducted in our country, partly in 
regional and mostly in schools (Berber and Anilan, 2018). The Ministry of National Education (MEB) is constantly innovating to solve the problems encountered in secondary education placement with the increasing number of students and schools (Taşkın ve Aksoy, 2018). The exams conducted in the schools in our country are conducted by the teachers of the current courses, while the exams administered centrally during the transition to secondary education are conducted by the Ministry of National Education (Birinci, 2014; Buyukozturk, 2016; Berber and Anilan, 2018; Cetin and Unsal, 2018). The level of success achieved through these exams, conducted locally and centrally by the Ministry of National Education, is of great importance for guiding students to their future (Hündür and Diken, 2018). In Turkey, some changes have been made over the years in terms of characteristics such as the application and content of the exam related to changes in education programs (Ormanc1, Cepni, and Ulger, 2018). In our country, the Ministry of National Education has made High School Entrance Exam (LGS) in 1999-2004, selection and Placement exam to secondary education (OKS) in 2004-2008, Placement Test (SBS) in 2008-2013 and transition from primary to secondary education exams(TEOG) in 2013-2018 (Ormanc1, Cepni, and Ulger, 2018; Buldur and Acar, 2019). In 2018, the Ministry of Education abolished the transition from the primary to Secondary Education (TEOG) system and replaced it with the High School Entrance Exam (LGS) (Taskın and Aksoy, 2018). The basic logic in this exam system is the address-based placement and that placement is optional (Atilgan, 2018). As of the 2018-2019 academic year, this exam was applied to 6th, 7th, and 8th. Graders and this exam was arranged by Provincial Directorates of National Education. The questions prepared in this exam were asked using the item pool of the Ministry of Education (Kuzu, Kuzu, and Gelbal, 2019).

The content of the TEOG system (MEB, 2013) is as follows.

* 8th-grade students enter the common exam from 6 basic courses; Mathematics, Science, Turkish, T.R. Revolution History and Kemalism, Foreign Language, Religious Culture and Moral Knowledge.

* The common exams are held centrally by the MEB every semester and are considered to be one of the written exam during the semester.

* The first of the courses with two written exams and the second of the courses with three written exams are made in the form of a common examination.

* In each common exam, 20 multiple choice questions with 4 options are asked and each question is evaluated as 5 points.

* Students take the common exams in their own schools except in cases of emergency and special circumstances.

* The teachers who take the exams are assigned to a different school than their own.

* For students who cannot take the common exam due to a valid excuse, an excuse exam is held.

The general characteristics of the LGS system (MEB, 2018a) are as follows.

* 6, 7 and 8th-grade students take the exam from 6 basic courses during the academic year; Mathematics, Science, Turkish, T.R. Revolution History and Kemalism, Foreign Language, Religious Culture and Moral Knowledge.

* Question distributions; 20 for Mathematics, Science and Turkish courses; and there are 10 questions for the courses of T.R. Revolution History and Kemalism, Foreign Language, Religious Culture and Moral Knowledge.

* In LGS, 3 incorrect answers leads 1 correct answer.

* LGS asks open-ended questions as well as multiple choice questions.

* Registration priority criteria for local placement are determined in the form of the student's preference order, the degree of proximity to home and the degree of proximity to the school.

When we look at the characteristics of TEOG and LGS systems, it is seen that questions are asked from the "Science" course in both exam systems. For this reason, it is thought that some of the glitches in the LGS may be taken into account in line with the views of the science teachers when applying the views of the science teachers for the comparison of these two exam systems. Therefore, science teachers' views were applied to compare the strengths and weaknesses of the TEOG system, which was implemented in previous years and then repealed, and the LGS systems, which came into force in 2018. In this research, the opinions of science teachers on the comparison of the TEOG system, which was abolished in 2017, and the LGS systems, which were enacted in 2018. Indeed, Diken (2018) stated that determination of the teachers' opinion towards current exam system's which closely interests all secondary school students in Turkey comparison with past systems that have been previously applied in our country would contribute the literature about the current exam system's implementation and would make it more systematic. Diken (2018) also stated that identifying teacher views on the weaknesses and strengths of the new exam system would 
contribute to the system's renewal, and could lead to suggestions that problems likely to be experienced or existing for the exam could be resolved. Guler, Arslan, and Celik (2019) stated that getting teachers' opinions which is the essential elements of the education system is important to reveal the strengths and weaknesses of the High School Entrance Exam (LGS) and it is worth considering in the revisions which will be made by Ministry of National Education Education (MEB) (Guler, Arslan and Celik 2019).

\section{Method}

\subsection{Research Pattern}

Structured questions were asked for science teachers to compare LGS and TEOG exams using the screening model. In this way, teachers' thoughts towards LGS and TEOG were identified. Science teachers who participated in the study were determined through simple probability (random) sampling, in which participants were selected by random method.

\subsection{Research Question and Sub-Questions}

The question of "What are the views of science teachers on comparing the transition from the primary to secondary education exam (TEOG) to the transition to high school exam (LGS)? Constitute the question of the study. The sub-questions of the study are:

1 - " Was it necessary to change the exam system and enact the LGS? "Why?"

2 - "Which exam system serves the purpose better up to this time? Why?"

3 - " What are the strengths of LGS according to TEOG?"

4 - " What are the weaknesses of LGS according to TEOG?"

\subsection{Working Group}

In the 2019-2020 academic year, the study group consists of 48 science teachers who are employed in 30 secondary schools in Kars City Center and selected by simple probability (random) sampling. Their teaching experience varies between "1-10 years", "between 10-20 years" and "over 20 years".

\subsection{Data Collection}

The data collection process was carried out with the official permission certificate obtained from Kars Provincial Directorate of National Education. Data collection tools were applied to science teachers in secondary schools in Kars city center during the spring semester of the 2018-2019 academic year. 48 science teachers working in 30 secondary schools in Kars province were asked to compare the TEOG and LGS systems and to write answers to these questions during a lesson period. The reason for getting opinions of science teachers in the research is because there are questions about the science learning field in the LGS exams which is currently applied and in TEOG, which was applied in our country in the previous years. The main problems and category were tried to be identified using explanatory and inferential codes that appeared in the analysis of forms for teachers' views (Miles \& Huberman, 1984). In determining the teachers' views on the comparison of the TEOG and LGS exam systems, the categories identified by the three expert researchers were re-checked and the consensus was reached. Besides, the categories identified in the comparison of the TEOG and LGS systems of the teachers in the study group were determined as frequency.

\subsection{Analysis of the Data}

Using the method of scanning in this study, the LGS system 48 science teachers' written opinions about the comparison of the LGS and TEOG system were read repeatedly by the researcher, main issues and categories were tried to be identified using the pre-determined descriptive and inferential codes that emerged in the analysis (Miles \& Huberman, 1984). The data analysis results were re-checked by three expert researchers using the" investigator triangulation technique" (Johnson \& Christensen, 2004). Following the determination of categories, consistency among expert opinions was found to be $84 \%$. Coders have worked together on cross-sections of data that are inconsistent. The researchers argued and reconciled until they adopted a common idea on the inconsistent data sections (Lincoln and Guba, 1985). The categories identified for the comparison of the TEOG and LGS systems of science teachers are tabulated in frequency form. The names of the science teachers involved in the research have been kept confidential. 


\section{Results}

The findings for the research are as follows.

"Did you think it was necessary to change the exam system and bring the LGS into effect? The categories of the responses of science teachers to the question and the frequencies of these categories are as shown in Table 1.

Table 1. Frequencies of Teachers Considering Whether LGS Should Be Enacted

\begin{tabular}{lc}
\hline & $\mathrm{f}$ \\
\hline LGS was required to enact & 15 \\
LGS was not required to enact & 33 \\
\hline
\end{tabular}

When Table 1 is examined, it is seen that 15 out of 48 science teachers think that the introduction of LGS is necessary, while 33 say that the introduction of LGS is not necessary. Looking at Table 1, it is noteworthy that most of the science teachers expressed the view that the TEOG system was more appropriate than LGS.

When science teachers who think that the introduction of LGS is necessary are asked the reason for this, the categories of their responses and the frequencies of these categories are as shown in Table 2.

Table 2. Teachers' Views on why It Is Necessary to Enact LGS

\begin{tabular}{lc}
\hline & $\mathrm{f}$ \\
\hline TEOG was not selective. The change of the exam system was in place. & 5 \\
LGS exam questions are quality, logical and based on reasoning & 2 \\
TEOG questions were very easy. The test had been made inattentively. & 2 \\
LGS' selectivity is high & 1 \\
TEOG directed the students rarely. That, in turn, lowered success in the long run. & 1 \\
Unfortunately, students do not listen carefully when the exam system does not change. & 1 \\
LGS improved students' critical thinking skills. & 1 \\
At LGS, the questions are more subtle and specific. & 1 \\
LGS is an exam requiring knowledge & 1 \\
\hline
\end{tabular}

When Table 2 is examined, most of the science teachers did not found the TEOG exam as selective, removing TEOG and enacting LGS was an appropriate decision, LGS has quality, sense, judgment-based, high selectivity, and specific questions requiring knowledge, LGS is done more carefully than TEOG, and they stated that LGS questions improve students' critical thinking skills.

When science teachers who feel that the introduction of LGS is not necessary are asked why the categories of their responses and the frequencies of these categories are as shown in Table 3. 
Table 3. Teachers' Views on Why It Is Not Necessary to Enact LGS

\begin{tabular}{ll}
\hline & $\mathrm{f}$ \\
\hline TEOG was a good practice & 5 \\
TEOG was more systematic. & 4 \\
TEOG was a process-driven test. & 4 \\
At LGS, student motivation towards the exam is dropping. & 2 \\
Changing the exam system is distressing. Students can't get used to the new system. & 2 \\
TEOG was more equitable. & 2 \\
TEOG was very good to do in two periods. & 2 \\
TEOG was more comprehensive and distinctive. & 1 \\
There must be continuity in the applied system. TEOG was a test with a continuum & 1 \\
TEOG appealed to all of the students. & 1 \\
It is difficult for students to be tested in a few hours with accumulated subjects. \\
TEOG was like a written exam that students always take. There was compensation. \\
Students should be evaluated process-oriented, not result-oriented. \\
Changing the exam system is distressing. Students can't get used to the system. \\
TEOG was a better assessment on the 6th, 7th, and 8th-grade basis. \\
Successful students at LGS will suffer. \\
I am amazed that the exam system is constantly changing. \\
Exam anxiety in students at LGS has dropped. There must have been some exam anxiety. \\
The TEOG system could be continued by correcting the missing situations. \\
\hline
\end{tabular}

When Table 3 was examined, many of the science teachers expressed their opinions on the "Why was it not necessary to change the exam system and enact the LGS?" question as TEOG was a beautiful, more systematic, process-oriented, raising student motivation, more equitable, process-oriented (conducted in two semesters), appealing to all students, compensable exam.

Some examples of the answers given by science teachers to the "Why was it not necessary to change the exam system and enact the LGS?" question are as follows.

"To me, TEOG was a better exam system. The missing parts should have been corrected and continued in the same system."

"No, it wasn't necessary. It is difficult for students to accumulate subjects and transfer information within a certain hour."

"In my opinion, it wasn't necessary. It was more appropriate for the old system to continue. As the weather warms up, students' motivation towards exam time decreases."

"I think the TEOG system was a more effective exam system. Because it was like written exams that students were always entering, and there were compensatory questions.

"Which exam system do you think serves the purpose better up to this time? The frequencies of the responses of science teachers to the question are as shown in Table 3.

"Which exam system do you think serves the purpose better?" the frequencies of the responses of science teachers to the question are as shown in Table 3. 
Table 4. Teachers' Views on Which Exam System Serves the Purpose Better

\begin{tabular}{ll}
\hline & $\mathrm{f}$ \\
\hline LGS & 13 \\
TEOG & 35 \\
\hline
\end{tabular}

When Table 4 was examined, it was determined that 13 out of 48 science teachers thought that LGS served the purpose better, while 35 thought that the TEOG system served the purpose better. Looking at Table 4, it is noted that most of the teachers of science express the view that the TEOG exam serves the purpose better.

The frequencies of the categories of the answers given by science teachers to the question" why LGS serves the purpose better" are as shown in Table 5 .

Table 5. Teachers' Views on Why LGS Serves the Purpose Better

\begin{tabular}{lc}
\hline & $\mathrm{f}$ \\
\hline High distinctiveness & 4 \\
LGS focused on understanding, interpretation, and results & 2 \\
Directs students to a suitable upper education & 1 \\
Far from rote, focused on the whole & 1 \\
It serves the purpose better & 1 \\
Students take the exam depending on their wishes & 1 \\
LGS has more subjects & 1 \\
In all classes (6., 7. and 8.), it involves students in teaching & 1 \\
Students study exam-oriented courses. & 1 \\
\hline
\end{tabular}

When Table 5 was examined, it was determined that the majority of science teachers responded to the question of why LGS serves the purpose better, as LGS is highly distinguishable, LGS is focused on understanding, interpretation, and results, LGS is a system that is far from recitation, focused on the whole, that serves the purpose, and it is a system that students voluntarily enter the exam.

The frequencies of the categories related to the answers given by science teachers to the "Why TEOG serves the purpose better" question is as shown in Table 6 .

Table 6. Teacher's Views on Why TEOG Serves the Purpose Better

\begin{tabular}{ll}
\hline & $\mathrm{f}$ \\
\hline TEOG's selectivity is high & 10 \\
TEOG is process-based & 8 \\
No residence-based student recruitment & 3 \\
TEOG is process-oriented & 3 \\
TEOG motivates the student & 2 \\
TEOG is a regular and systematic exam & 2 \\
Placement is better done in TEOG & 2 \\
TEOG serves the purpose better & 1 \\
TEOG is suitable for the curriculum & 1 \\
TEOG is an exam for students & 1 \\
TEOG questions are not hard & 1 \\
At TEOG, the student was working harder. & 1 \\
\hline
\end{tabular}


When Table 6 examined most of the science teachers expressed their opinions on the "why TEOG better serve the purpose" question as; TEOG is highly selective, process-based, no address-based placement, students are positively motivated, organized, systematic, process-oriented, placement is more fair, suitable with the curriculum.

Some examples of the answers given by science teachers to the "Why LGS serves the purpose better" question is as follows.

"The LGS system is beautiful as the aim is to direct students to a suitable upper education. Only high-level students are placed in the schools to be entered through the exam. I think there should be a different form of placement for schools without exams."

"I find the LGS exam more accurate. In the selection exam, the best ones have to be chosen, and this exam succeeds in this goal."

"I think the LGS exam is better. Only the 8th class subjects were included in the TEOG exam. But on the LGS exam, 5, 6, 7, and 8th class subjects were included."

"I think it's more appropriate to do it separately in 6th, 7th, and 8th grades. Because it covers the whole process, not for a year."

Some examples of the answers given by science teachers to the question" why TEOG serves the purpose better" are as follows.

"TEOG. Because the distinction of the TEOG exam was high and could be used to distinguish students at all levels."

"The TEOG system. Because both the curriculum was more limited and the student was preparing for the exam in a more concentrated way."

"TEOG. A more regular structure of this system, the address-based school attendance situation has simplified the system and education. The fact that most high schools are scoreless has weakened the system."

"TEOG. Because it's more organized and systematic. In this exam system, the status of attending the closest school to home based on the address is a weakness. The fact that most high school types are scoreless is a weakness of the system."

"What are the strengths of LGs according to TEOG?" the frequencies of the responses of science teachers to the question are as shown in Table 7.

Table 7. Teacher Views on the Strengths of LGS According to TEOG

\begin{tabular}{lc}
\hline & $\mathrm{f}$ \\
\hline Questions based on interpretation & 10 \\
Some questions improve the ability to think analytically and logically & 10 \\
It's very good at reading. & 8 \\
High distinctiveness and selectivity of questions & 7 \\
Less exam anxiety & 4 \\
Questions require knowledge & 2 \\
There are questions based on high-level thinking & 2 \\
The questions cover all topics & 1 \\
Far from rote & 1 \\
Impact of grades given in schools has diminished & 1 \\
No strengths & 1 \\
Better quality of the exam & 1 \\
\hline
\end{tabular}


When Table 7 was examined, it was determined that teachers expressed their opinions when the strengths of LGS compared to TEOG were asked as the questions in the LGS were based on interpretation, the questions developed analytical and logical thinking ability, very good at reading comprehension, had higher distinctiveness and selectivity, required knowledge, have more quality, require high-level thinking, students have less stress when preparing for LGS, the effect of school scores decreased.

Some examples of teachers' responses to the "What are the strengths of LGS' compared to TEOG?" question are as follows.

"TEOG is a test where more hardworking students can succeed. I think LGS is an exam that tests students' abilities as well as their hard work because its questions have a high difficulty level."

"No aspect of it is strong. They gave 60 minutes to the science section last year. The questions were long and extensive. The students couldn't finish the questions. It's a complete failure, as usual."

"The questions are stronger and more distinctive. Reading and comprehension are more dominant."

"LGS requires the ability to interpret what you understand and analytical thinking. It is a system that is far from rote."

"Changing the name of the exam, not changing the content, poses problems for the student. For a student who is used to a certain system, changing the system every year is a difficult situation. A detailed plan should be made in advance for the change and the system should be used for a long time."

"What are the weaknesses of LGS according to TEOG?" the frequencies of the responses of science teachers to the question are as shown in Table 8.

Table 8. Teachers' Views on the Weak Side of LGS According to TEOG

\begin{tabular}{lc}
\hline & $\mathrm{f}$ \\
\hline Implementation once a year and in one session & 12 \\
Lack of inter-session time & 5 \\
Lack of a chance to make compensation & 5 \\
No weak sides & 5 \\
Inability to appeal to all students & 5 \\
It only covers the 8th class & 3 \\
Excess accumulation of subjects & 2 \\
Inability to motivate students to take the exam & 1 \\
The wrong leads the truth & 1 \\
The exam takes places towards the end of the semester & 1 \\
Too much detail of questions & 1 \\
Small number of questions & 1 \\
Decreased impact of written exams & 1 \\
Difficult questions & 1 \\
Some schools lack cover/quota & 1 \\
Questions are long & 1 \\
Students' exam anxieties are too much & 1 \\
Decreased impact of written exams & 1 \\
\hline
\end{tabular}

When Table 8 was examined, it was found that most of the science teachers reported that the weaknesses of the LGS compared to TEOG were that the LGS applied once a year in one session, could not appeal to all students, there was no break between sessions, the subjects accumulated too much in the LGS, had no chance to compensate, the questions were long, decreased the importance of written exam, could not motivate the students.

"What are the weaknesses of LGS according to TEOG?" some examples of teachers' responses to the question are as follows. 
"TEOG performed in all classes (6, 7, and 8th) the exam score of the classes is valid and it also replaces the written exam."

At LGS, students are unable to set goals for themselves. It is easier to go to any high school. They are unable to set goals during the preparation process for the exam."

"At the end of the year in terms of a single exam, we are experiencing difficulties in motivating students to take the exam."

"In TEOG, there was 40 minutes of exams, 40 minutes of break. There was a two-day exam session. Students were not stressed because TEOG was conducted in 1st and the 2nd semester separately.

"Because it was a new system, there was a problem of adaptation, and deficiencies in students' pre-learning led to a lack of motivation."

"It appeals to a certain segment of students. The questions should be medium, low, and difficult so that the scope validity is high."

"Students are not as well prepared for LGS as they are at TEOG and we have difficulty motivating them to take the exam"

\section{Discussion}

The study found that most science teachers thought that the introduction of LGS was not necessary, but that TEOG should continue. When science teachers were asked why it was not necessary for the change of the TEOG system and the introduction of LGS, it was determined that the TEOG was a beautiful, more systematic, process-oriented, student-motivated, more equitable, appealing to all students, compensatory, continuous, two-term exam. In their study, Kizkapan and Nacaroglu (2019) found that teachers reported taking the TEOG exam on different days and in different sessions lowered the anxiety and stress levels of students. In their study, Taskin and Aksoy (2018) determined that the score taken from the exam in the TEOG system which was applied before the LGS was taken as a substitute for the first or second written exam and that the exam only covered the subjects up to the date of the exam was viewed positively by the teachers. Ozkan and Ozdemir (2014) have stated that the TEOG system is much more motivating for students to take the exam in their schools, the spread of the exam over two periods, making a make-up exam, the wrong answers do not lead to the right answers, and TEOG system has strong sides. In their study (2014), Ozturk and Aksoy concluded that one of the most positive aspects of the TEOG system is an exam that spans two days in each semester instead of a single exam. In their study, Zorlu and Zorlu (2015) found that TEOG reduced exam anxiety in students. Calıskan (2011) has the opinion that TEOG can positively affect student achievement, that the system will give students the habit of studying regularly, that absences will be reduced, and that the effect of the exam on the written exam score may also be motivating. In their study, Sad and Sahiner (2016) show that thanks to the TEOG system, the importance of teachers and courses will increase as well as the importance of the school, students' interest and motivations for the lessons will be positively affected by this situation and student absences may decrease.

In this study, it was found that there were also science teachers who, although not as much as the TEOG system, welcomed the enactment of LGS. Considering the views of science teachers who think that it is necessary to abolish the TEOG and enact the LGs, it is determined that these teachers are not selective, that the LGs exam questions are high quality, logical, reasoning-based, selective, information-demanding, eliminative and specific questions. It was also determined that TEOG was a non-selective test that was conducted carelessly, directed students to rote, and reduced success in the long term.

In the study, it was determined that the majority of the teachers thought that the exam was the one that best served the purpose of TEOG, considering the opinion of the science teachers on "which exam system served the purpose better in the exams conducted up to this time". When the science teachers were asked the reason for this, it was found that the teachers expressed the opinion that TEOG was highly selective, based on process, motivating the student, appropriate to the curriculum, regular and systematic, student-wise, placement was fairer, there was no address-based student placement, and exam questions did not compel the students. In this study, it was determined that there were also science teachers who thought that the LGS system served the purpose better in the exams, although not as much as TEOG. When science teachers were asked why LGS serves the purpose better, they expressed the opinion that LGS is a system of exam that is highly distinguishable, far from recitation, focused on the whole, with questions focused on understanding, interpretation, and conclusion, depending on their wishes for the 
students to take the exam. In their study, Ozden et al. (2014) found that the questions asked in the TEOG exam were more in the level of knowledge and understanding. Kizkapan and Nacaroglu also (2019) determined that in their study, questions that asked in LGS require higher-level thinking skills. It is observed in the Ministry of National Education Transition to Secondary Education Directive that exam questions are prepared to measure students' reading comprehension, problem-solving, inference, interpretation, critical thinking, analysis, scientific process skills, and similar high-level skills (MEB, 2018a). In their study, Kizkapan and Nacaroglu (2019) found that LGS questions are understandable, clear, distinctive and multifaceted, but that teachers have expressed the opinion that the time given at LGS is not sufficient to answer the questions. In the report prepared by the MEB on the results of the central exam in 2018, it is stated that the science questions that asked in the exam were of medium difficulty and capable of distinguishing the students (MEB, 2018b). Besides, Kizkapan and Nacaroglu (2019) found that in their study, LGS creates stress-pressure on students and that there are no positive effects of this system on students' attendance. Kizkapan and Nacaroglu (2019) also found that teachers stated that LGS contributed to the more planned-programmatic work of students, but that doing LGS in two sessions on the same day reduced students' achievements and motivations. Akman (2017) found that teachers expressed opinions that the LGS distributed over two days in two periods, such as the TEOG exam, would increase student motivation. In this study, it was found that most science teachers thought that LGS had more weaknesses than TEOG. When science teachers were asked about the weak aspects of LGS compared to TEOG, teachers reported that LGS was applied once a year and in one session, could not address all students, had no time between sessions, had too much accumulation of subjects, had no chance to compensate, had decreased the impact of written exams, could not motivate students, had too much of the exam anxieties, had a little number of questions, had long, difficult and detailed questions, it was wrong to make it at the end of the semester since subjects accumulated. In his study, Erol (2016) determined that TEOG had a positive impact on students' exam performance. Hundur and Diken (2018) stated that science teachers expressed positive views towards TEOG and that in the light of these positive views, the teachers for TEOG could give an idea to correct the applications they found lacking in LGS. Ozkan, Guvendir, and Satici (2016) determined that the application of the TEOG exam on different days meant that students were relieved to be in the same class as their classmates when they took the exam at their school. Gökulu (2015) found that teachers expressed their views on the preparation of questions in the TEOG exam by experts, giving equal importance to all subjects and ensuring the validity of the questions in scope. Again, when the studies towards TEOG is examined (Argon and Soysal, 2012; Gündogdu et al., 2010; Karadeniz, Er and Tangulu, 2014; Zayimoğlu-Ozturk and Aksoy, 2014) it is observed that these studies have identified teacher views that the TEOG system reduces students' exam stress. Gormez and Coskun (2015) found that the TEOG system was conducted in the form of multiple exams, students taking exams in their schools, having make-up exams, having half an hour of rest between exams and taking exams from a single course in each session were important factors in reducing students' stress and anxiety. Besides, Gormez and Coskun (2015) found that the TEOG exam was performed twice a year and in the form of 40-minute exams were received positively by a significant proportion of science teachers. In their study, Atilla and the Ozekenli (2015) stated that conducting the exams twice in a year; give parents, students, and teachers the opportunity to evaluate the scores from the first exam, students have enough time to answer the questions of the exam and rest since it is done in a 40-minute session and because of these reasons, it is a useful application. In their study, Atilla and Özekenli (2015) found that the use of the school achievement score in conjunction with TEOG was important in terms of increasing the importance of the school. In this study, it was found that there were also science teachers who thought that LGS had strengths compared to TEOG. When science teachers were asked "What are the strengths of LGS compared to TEOG?" they expressed their opinions as; LGS questions based on interpretation, require information, differentiation, and high selectivity, covering all topics, higher-level thinking, based on analytical skills and logical thinking develops, and away from the rote, based on reading comprehension, have better quality. In their study, Ozden et al. (2014) found that the TEOG exam included fewer types of questions that measure upper cognitive skills such as reasoning, analyzing, and graphical interpretation and that students at LGS reported that the exam was fairer as exam concerns were less and the impact of grades given in schools decreased. Besides, Ozden et al (2014) found that very few of the science exam questions in the TEOG exam measured senior thinking skills, multiple-choice tests were insufficient to measure senior cognitive traits defined as broad thinking levels, so program gains were not adequately represented in the exam. Taskin and Aksoy (2018) stated that to ensure the differentiability of the questions in the central exams, questions should be asked and correction formula should be applied to the level that can measure the high-level cognitive skills. As a result of this research, the views of science teachers on the strengths and weaknesses of the transition from primary to secondary education (TEOG) exam were determined in line with the current High School Entrance Exam (LGS). In light of the results of this research, it is the greatest wish that the strong sides of the TEOG system can be integrated into the LGS and made a more purposeful exam. Besides, it is thought that applying the 
opinions and suggestions of teachers in different branches of all secondary schools (Mathematics, Turkish, Social Sciences) regarding the strong and weak aspects of LGS can contribute to making this exam system more systematic and beautiful. As Taskin and Aksoy (2018) stated, perhaps in the later times in our country, teachers' opinions may also contribute to the important presence of students in the transition to high schools, where even the excitement and stress may be possible to remove the complete exams.

\section{Acknowledgments}

I hereby thank Dr. Lecturer Ali Ibrahim Can Gozum for contributing to the design of the article.

\section{References}

Atilgan, H. (2018). The transition between stages in Turkey: past-present and a model proposal. Ege Journal of Education, 19(1), 1-18. https://doi.org/10.12984/egeefd.363268

Akman, O. (2017). Views of the ninth graders on the transition exams from primary to secondary education. (Unpublished Master's Thesis), Bartin University, Institute of Educational Sciences, Bartin. https://doi.org/10.7827/TurkishStudies.12333

Argon, T., \& Soysal, A. (2012). Teacher and student opinions on the placement exam. International Journal of Human Sciences, 9(2), 446-474.

Atilla, M. E., \& Özekenli, D. F. (2015). The transition from primary to secondary education: what do science teachers think? Ondokuz Mayis University Journal of the Faculty of Education, 34(1), 124-140.

Berber, A., \& Anilan, B. (2018). Exam of teacher candidates' views on the science field questions in the last ten years transition from primary to secondary education exams. Turkish Studies, 13(27), 203-224. https://doi.org/10.7827/TurkishStudies.14601

Birinci, D. K. (2014). First experience in the central system common exams: mathematics course. Journal of Education and Training Research, 3(2), 8-15.

Buldur, P., \& Acar, M. (2019). Views of secondary school teachers towards central exams. Kastamonu Journal of Education, 27(1), 319-330. https://doi.org/10.24106/kefdergi.2546

Buyukozturk, Ş. (2016). Thoughts on the exams. Journal of Education and Human Sciences, 6(2), 345-356. https://doi.org/10.23863/kalem.2017.64

Can, E. (2010). The place of central exams in the Turkish education system. National assembly of educational sciences. International Cyprus University Faculty of Education, Nicosia, TRNC. Retrieved from http://www.pegem.net/akademi/kongrebildiri_detay.aspx?id=122786.

Can, E. (2017). Determination of the effects of central exams according to student views. Journal of Academic Social Research, 5(58), 108-122. https://doi.org/10.16992/ASOS.12842

Caliskan, H. (2011). Teachers' opinions concerned common exams administered in elementary schools. China Education Review, 8(5), 615-626.

Cetin, A., \& Unsal, P. (2018). Social, psychological impact of central exams on teachers and reflections of teachers on curriculum practices. Journal of Hacettepe University Faculty of Education, 34(2), 304-323. https://doi.org/10.16986/HUJE.2018040672

Cepni, P., Ozsevgec, T., \& Gokdere, M. (2003). Exam of SSE physics and high school physics questions according to cognitive development and formal operation period characteristics. Journal of National Education, 57(1), 30-39.

Diken, E. H. (2018). The opinions of science teachers and 8th graders on the examination anxieties of the transition from primary to secondary education (TEOG) exam (the case of Kars province). Journal of Humanities and Social Sciences Research, 7(2), 718-741. https://doi.org/10.15869/itobiad.376591

Dinc, E., Dere, I., \& Koluman, P. (2014). Opinions and experiences on transition applications between grades. Adiyaman University the Institute of Social Sciences Journal, 7(17), 397-423. https://doi.org/10.12780/UUSBD372

Erol, H. (2016). The opinions of social studies teachers on the questions about the course of "T.R. Revolution History and Kemalism" in TEOG. Electronic Social Science Journal, 15(57), 548-567. 
https://doi.org/10.17121/ressjournal.302

Gokulu, A. (2015). Examination of science and technology teachers' written exam questions and science and technology questions asked in TEOG exams according to the renewed bloom taxonomy. Route Educational and Social Science Journal, 2(2), 434-446. https://doi.org/10.17121/ressjournal.302

Gormez, M., \& Coskun, I. (2015). Evaluation of the transition reform from primary to secondary education in the 1st year. Foundation for Research on Politics, Economics, and Society, Ankara.

Guler, M., Arslan Z., \& Celik, D. (2019). Math teachers' opinions on the 2018 High School Entrance Exam. YYU Journal of Faculty of Education, 16(1), 337-363. https://doi.org/10.23891/efdyyu.2019.128

Gundoğdu, K., Kızıltas, E., \& Cimen, N. (2010). Student and teacher opinions on the placement test (SBS) (the case of Erzurum province). Elementary Online, 9(1), 316-330.

Hundur, T., \& Diken E. H. (2018). Examination of the opinions of science teachers for the transition from basic education to secondary education (TEOG) in terms of some variables. Caucasian Journal of Science, 5(1), 12-29.

Karadeniz, O., Er, H., \& Tangulu, Z. (2014). Metaphorical perceptions of 8th graders towards SBS. International Journal of Eurasian Social Sciences, 5(15), 64-81.

Kizkapan, O., \& Nacaroglu, O. (2019). Science teachers' opinions on central examinations (LGS). Nevsehir Haci Bektaş Veli University SBE Journal, 9(2), 701-719.

Kuzu, Y., Kuzu, O., \& Gelbal, P. (2019). Examination of TEOG and LGS systems from the point of view of students, teachers, and parents. Ahi Evran University Institute of Social Sciences Journal, 5(1), 112-130. https://doi.org/10.31592/aeusbed.559002

Lincoln, Y. S., \& Guba, E. G. (1985). Naturalistic inquiry. Beverly Hills, we have Sage.

MEB. (2013). Frequently asked questions about transition from primary to secondary Retrieved 02.07.2019 from http://www.meb.gov.tr/duyurular/duyurular2013/bigb/tegitimdenoogretimegecis/MEB_SSS_20_09_2013.pdf

MEB. (2018a). Ministry of national education transition to secondary education directive. Retrieved 20.07.2019 from https://www.meb.gov.tr/meb_iys_dosyalar/2018_03/26191912_yonerge.pdf

MEB. (2018b). 2018 Transition system to high schools (LGS): performance of students placed by central examination. Educational Analysis and Evaluation Reports Series, MEB, and Ankara.

Miles, M. B., \& Huberman, A. M. (1984). Qualitative data analysis: a sourcebook of new methods. CA: Sage

Ormanci, U., Cepni, P., \& Ulger B. B. (2018). Science teachers' opinions on the transition to secondary education common examinations. Academic Journal of Educational Sciences, 2(1), 1-15. https://doi.org/10.31805/acjes.422031

Ozden, M., Akgun, A., Cinici, A., Sezer, B., Yildiz, P., \& Tas, M. M. (2014). Analysis of central system common examination science questions according to Webb's depth of knowledge levels. Adiyaman University Journal of Natural and Applied Sciences, 4(2), 91-108.

Ozkan, M., \& Ozdemir, B. E. (2014). 8th-grade students' and teachers' opinions on the central common examinations applied in the transition to secondary education. Journal of History School, 7(20), 441-453. https://doi.org/10.14225/Joh641

Ozkan, Y. O., Guvendir, M. A., \& Satici, D. K. (2016). Student opinions on the application conditions of the TEOG exam. Theory and Practice in Education, 12(6), 1160-1180.

Ozkan, Y. O., \& Guvendir, M. A. (2018). Developing the teacher scale to determine the instructional and affective effects of central exams on teachers. Inonu University Journal of Faculty of Education, 19(3), 189-204. https://doi.org/10.17679/inuefd.394383

Ozturk, F. Z., \& Aksoy, H. (2014). Evaluation of the transition model from primary to secondary education according to the 8th-grade student opinions (the case of Ordu Province). Ondokuz Mayis University Journal of the Faculty of Education, 33(2), 439-454.

Sad, P. N., \& Sahiner, Y. K. (2016). Student, teacher and parent opinions on the transition from primary to secondary education (TEOG) system. Elementary Online, 15(1), 53-76. https://doi.org/10.17051/io.2016.78720

Taskin, G., \& Aksoy, G. (2018). Expectations of students and teachers from the transition system to secondary education in light of the opinions about the TEOG system. International Journal of Active Learning, 3(1), 19-43. 
Yapici, H. (2016). Social studies teachers' opinions on the transition from primary to secondary education (TEOG) exam. International Periodical for the Languages, Literature, and History of Turkish, 11(21), 437-450. https://doi.org/10.7827/TurkishStudies.11276

Zayimoğlu-Ozturk, F., \& Aksoy, H. (2014). Evaluation of the transition model from primary to secondary education according to the 8th-grade student opinions (the case of Ordu Province). Ondokuz Mayis University Journal of the Faculty of Education, 33(2), 439- 454.

Zorlu, Z., \& Zorlu, F. (2015). Levels of students' and teachers' opinions about the learning environment in science and technology courses. Route Educational and Social Science Journal, 2(1), 103-114. https://doi.org/10.17121/ressjournal.215 